\title{
Human papillomavirus-independent cervical cancer
}

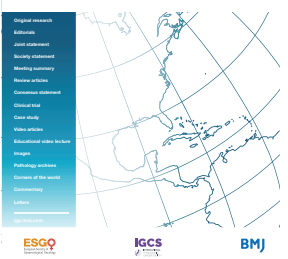

For numbered affiliations see end of article.

\section{Correspondence to}

Dr Rene Pareja, Department of Gynecologic Oncology, Instituto Nacional de Cancerologia, Bogota, Colombia; ajerapener@ gmail.com

Received 12 August 2021 Accepted 18 0ctober 2021 Published Online First 1 November 2021

\section{SLinked}

- http://dx.doi.org/10.1136/ ijgc-2021-003250

Check for updates

(C) IGCS and ESGO 2022. No commercial re-use. See rights and permissions. Published by BMJ.

To cite: Fernandes $\mathrm{A}$, Viveros-Carreño D, Hoegl J, et al. Int J Gynecol Cancer 2022;32:1-7.

Andreina Fernandes (D) ," David Viveros-Carreño (i) , ${ }^{2}$ Jorge Hoegl (D) , ${ }^{3}$ Maira Ávila, ${ }^{1}$ Rene Pareja (1) 2,4

\section{ABSTRACT}

Cervical cancer is the fourth most frequent cancer in women worldwide, representing nearly $8 \%$ of all female cancer deaths every year. The majority of cases of cervical cancer are caused by human papillomavirus (HPV); however, up to $5 \%$ of tumors are not associated with HPV-persistent infection and, moreover, the new WHO Female Genital Tumors classification subdivided cervical squamous and adenocarcinomas into HPV-associated and HPV-independent tumors. Based on this new information, the aim of this review is to provide an overview of HPVindependent cervical cancer, evaluating diagnostic techniques, molecular profiles, and clinical outcomes. The HPV-independent tumors are characterized by a differentiated molecular profile with lower proliferative activity, a p53 immunostaining, a decreased expression of cyclin-dependent kinase inhibitor proteins, such as p16, p14, and p27, and alterations in PTEN, p53, KRAS, CTNNB1, ARID1A, and ARID5B. HPV-independent tumors are associated with both adenocarcinomas and squamous histologic subtypes, with lymph node involvement in the early stages, more distant metastasis, and generally worse oncological outcomes. Thus far, no specific therapeutic strategies have been developed based on HPV status; however, with advancing knowledge of differences in the molecular profiles and possible targetable alterations, novel approaches may offer potential options in the near future. Investigators should report on clinical outcomes, evaluating the overall response rates to specific treatments, and consider new biomarkers to establish more accurate prognostics factors.

\section{INTRODUCTION}

Cervical cancer is the fourth most frequent cancer in women, with 604127 new cases in 2020 and more than 341831 deaths, representing nearly $8 \%$ of all female cancer deaths every year. ${ }^{1}$ of the estimated incidence and mortality from cervical cancer, approximately $84 \%$ of all cases and $88 \%$ of all deaths occurred in low- and middle-income countries. ${ }^{2}$ Human papillomavirus (HPV) is a sexually transmitted virus that, if it establishes a persistent infection with high-risk genotypes, such as HPV 16 and 18, there is high association with cervical cancer. ${ }^{3}$ Both of the HPV sub-types jointly cause $70-75 \%$ of all cervical cancers and $40-60 \%$ of its precursor lesions. ${ }^{2}$

Epidemiological studies report that almost all cases of cervical cancer are caused by $\mathrm{HPV}^{3}$; however, approximately $5 \%$ of tumors are not associated with
HPV-persistent infection. ${ }^{4}$ In 2009, zur Hausen stated that although more than $95 \%$ of cervical cancer biopsies contain high-risk HPV genomes, this does not necessarily imply that all of these tumors are caused by the infection. ${ }^{5}$ A meta-analysis involving 40679 women with cervical cancer from 229 studies, that used broad-spectrum consensus polymerase chain reaction (PCR) assays based on the primers MY09/11, PGMY09/11, GP5+/6+, SPF10, SPF1/GP6+, or L1C1/ L1C2, reported that $10.6 \%(8.4-13.9 \%)$ of cases were HPV-negative and this percentage varied with geographic location. ${ }^{6}$

In 2020, the WHO updated the Female Genital Tumors classification (5th edition) and recognized that a proportion of cervical cancers are not associated with HPV infection, especially adenocarcinomas. ${ }^{7}$ Based on this statement the Tumor Editorial Board subdivided the cervical squamous lesions into HPVassociated and HPV-independent tumors, and adenocarcinomas into HPV-associated, including (1) usual type: villoglandular variant; (2) mucinous type: mucinous not otherwise specified (NOS) adenocarcinoma, intestinal adenocarcinoma, signet-ring cell adenocarcinoma, and stratified mucin-producing adenocarcinoma, and HPV-independent tumors, including (1) gastric type adenocarcinoma; (2) clear cell adenocarcinoma; (3) mesonephric adenocarcinoma; and (4) endometrioid adenocarcinoma. ${ }^{7}$

The aim of this review is to provide an overview of HPV-independent cervical cancer, evaluating diagnostic techniques, molecular profiles, and clinical outcomes.

\section{HPV Tests: Screening and Genotyping}

HPV-independent cervical cancers are clinically relevant due to their biological behavior and possible worst prognosis. HPV-negative status may be associated with different potential scenarios: (1) HPVindependent (true negative) cancers, such as some subtypes of adenocarcinomas and a few cases of squamous carcinoma; (2) loss of the HPV genome during the integration process; (3) presence of viral genotypes not included in the molecular tests; (4) failure in detection of the diagnostic method employed; or (5) misclassification of cancers as primary cervical (metastases or primary uterine corpus neoplasms). ${ }^{489}$ 
Table 1 HPV test FDA approved for cervical cancer screening ${ }^{161724}$

\begin{tabular}{|c|c|c|c|c|c|c|}
\hline $\begin{array}{l}\text { Commercial } \\
\text { name }\end{array}$ & Assay type & Genotypes & $\begin{array}{l}\text { Target } \\
\text { genes }\end{array}$ & Analytical sensitivity & $\begin{array}{l}\text { Sensitivity } \\
\%(95 \% \mathrm{Cl})\end{array}$ & $\begin{array}{l}\text { Specificity } \\
\%(95 \% \mathrm{Cl})\end{array}$ \\
\hline $\begin{array}{l}\text { Hybrid Capture } \\
\text { System } 2^{* 1}\end{array}$ & $\begin{array}{l}\text { Signal } \\
\text { amplification }\end{array}$ & $\begin{array}{l}13 \mathrm{HR}-\mathrm{HPV} \\
5 \mathrm{LR}-\mathrm{HPV}\end{array}$ & $\begin{array}{l}\text { Whole viral } \\
\text { genome }\end{array}$ & 1000-5000 copies/reaction & 92.7 (85.6 to 97.0 ) & 39.4 (33.1 to 46.0$)$ \\
\hline Cervista-HR*2 & & $14 \mathrm{HR}-\mathrm{HPV}$ & $L 1 / E 6 / E 7$ & 1250-7500 copies/reaction & 92.8 (83.9 to 97.6 ) & $46,0(44.2$ to 47.0$)$ \\
\hline Cervista $16 / 18^{3}$ & & 16,18 & $L 1 / E 6 / E 7$ & 625-1200 copies/reaction & 77.3 (56.6 to 89.9$)$ & 67.3 (63.9 to 70.6$)$ \\
\hline Cobas HPV Test ${ }^{4}$ & $\begin{array}{l}\text { DNA } \\
\text { amplification }\end{array}$ & $\begin{array}{l}16,18+ \\
12 \mathrm{HR}-\mathrm{HPV}\end{array}$ & $L 1$ & $150-1200$ copies/mL & 93.5 (82.5 to 97.8$)$ & 69.3 (66.9 to 71.5$)$ \\
\hline $\begin{array}{l}\text { BD Onclarity HPV } \\
\text { assay }^{5}\end{array}$ & & $\begin{array}{l}16,18,45+ \\
11 \text { HR-HPV }\end{array}$ & $E 6 / E 7$ & 251-2367 copies/mL & 91.4 (77.6 to 97.0$)$ & $62.0(59.6$ to 64.4$)$ \\
\hline $\begin{array}{l}\text { APTIMA HPV } \\
\text { assay }^{6}\end{array}$ & $\begin{array}{l}\text { mRNA } \\
\text { amplification }\end{array}$ & $\begin{array}{l}16,18,45+ \\
11 \text { HR-HPV }\end{array}$ & $E 6 / E 7$ & 19-239 copies/reaction & 97.7 (92.0 to 99.4 ) & $52.9(49.1$ to 56.6$)$ \\
\hline
\end{tabular}

*Does not determine specific type. 1: Qiagen, USA; 2: Hologic Inc, USA; 3: Hologic Inc, USA; 4: Roche Molecular Systems Inc, USA; 5: Becton Dickinson, USA; 6: Hologic Inc, USA.

FDA, US Food and Drug Administration; HPV, human papillomavirus; HR-HPV, high risk HPV; LR, low risk HPV.

The WHO initiative on preventive strategies for eradication of cervical cancer include HPV vaccination in combination with the implementation of effective screening programs with HPV-based testing for risk estimation of CIN3 +, and the proper management of pre-invasive lesions and cervical cancer. ${ }^{10}{ }^{11}$ Therefore, it is important to select an appropriate and validated test in terms of clinical accuracy, reproducibility, and cost-effectiveness before screening implementation. ${ }^{12-14}$ In general, molecular tests are widely used in epidemiological studies, during HPV surveillance, and in monitoring the impact of HPV vaccination. ${ }^{15}$

HPV testing is a highly sensitive technique with high negative predictive value $(97.9-99.3 \%)^{12} 16$; however, the optimal performance of an HPV test depends on a large number of factors such as sample collection, nucleic acid extraction methodology, primers, and use of internal controls. ${ }^{17}$ The most commonly used methods to detect the HPV genome are based on PCR and the use of hybridization probes targeting the $L 1$ gene, as this is the most conserved gene in the HPV genotypes. ${ }^{18}$ These tests are highly sensitive and specific (Table 1); however, they may not be capable of detecting HPV genomes that do not specifically bind to the designed primers and probes, and therefore a viral genotype that diverges in genomic sequence from the designed primer/probe sequences may escape amplification and/or hybridization and remain undetected. ${ }^{19-21}$

There are currently commercial tests approved by the US Food and Drug Administration for cervical cancer screening based on viral DNA amplification and mRNA amplification. Another group include signal amplification systems (Table 1). Signal amplification methods have a lower sensitivity than DNA amplification methods and may cause false negatives, especially in cases where the viral load is low. In addition, the absence of an internal control increases the proportion of false negatives, likely due to degradation of the viral genome. ${ }^{22} 23$ Most PCR-based tests only amplify the $L 1$ region of the virus. Therefore, PCR false negatives may be associated with the loss of this region during the viral integration process ${ }^{24}$; whereas the E6/E7 mRNA expression evaluation could be associated with the presence of a high-grade lesion or cervical cancer, since it is known that the E6/E7 mRNA proportion increases after integration of the viral genome into host cells. ${ }^{24}$

Due to variations in the methodological approaches used to detect HPV, different primers, and diverse sensitivities and specificities, Petry et $\mathrm{al}^{25}$ recommend the use of an additional PCR-based test as a part of the differential diagnosis of possible HPV-negative cervical cancer. However, when HPV detection fails by the conventional methodologies, other molecular techniques such as high-throughput sequencing can be used to identify the specific genotype in case of HPV infection. Likewise, if the cDNA is sequenced, the data can show whether there is transcriptional activity of the virus, which is fundamental in both the initiation and maintenance of the malignant phenotype. ${ }^{26}{ }^{27}$ The evidence shows that in cases of re-testing of suspected HPV-independent tumors, especially those performed with deep sequencing, between $48-57 \%$ of cervical cancer samples with a negative result by PCR remain truly negative ${ }^{28}$ both in cases of adenocarcinomas and squamous cell carcinomas.

\section{Molecular Profile of HPV-Independent Tumors}

The HPV carcinogenesis associated with the development of cervical cancer is well described ${ }^{3}$; however, the mechanism associated with HPV-independent cancers is unclear. ${ }^{29}$ Several studies have evaluated the differential gene expression between the HPVassociated and HPV-independent cervical cancers. ${ }^{4031}$ There are differences in the expression of markers between HPV-positive and HPV-independent tumors, evaluating cell proliferation markers such as PCNA ${ }^{32}$ and $\mathrm{Ki}^{3} 7^{33}$; tumor suppressor proteins such as $\mathrm{p} 53{ }^{33-37} \mathrm{p} 16{ }^{35-38} \mathrm{p} 14, \mathrm{p} 21$, and $\mathrm{p} 27^{36}$; and proto-oncogenes such as epidermal growth factor receptor (EGFR), ${ }^{33} \mathrm{c}$-myc, ${ }^{34}$ and c-Erb$2^{33}$

The HPV-independent tumors have a lower proliferative activity, suggesting that the viral infection induces an increased cellular proliferation. ${ }^{32}$ Additionally, HPV-independent tumors show p53 nuclear immunostaining, and thus a useful marker in the differentiation of the viral independent tumors. ${ }^{33-36}$ Nicolás et $\mathrm{al}^{37}$ reported that tumors with an HPV-negative result showed a high rate of p53 abnormal (p53abn) immunostaining pattern, suggesting a mutational phenotype associated with the capacity of tumor deregulation, with increased growth potential and metastasis. Finally, HPV-positive tumors show increased expression of cyclindependent kinase (CDK) inhibitor proteins, such as p16, p14, and p27, ${ }^{36}$ as a surrogate marker of HPV infection. ${ }^{38}$ 
With the developmentand implementation of novel moleculartechniques, the comparison of genetic profiles between HPV-associated and HPV-independent tumors has been possible. ${ }^{430313940}$ WIG-1 is a p53-regulated gene that encodes a transcription factor. WIG-1 can interact with heterogeneous nuclear ribonucleoprotein (hnRNP A2/B1), RNA helicase A, and double strand RNA (dsRNA), which plays an important role in RNA and protein stabilization. ${ }^{41}$ WIG-1 is frequently amplified in tumors, including cervical cancer. ${ }^{39}$ WIG-1 mRNA expression was higher in the HPV-independent cervical cancer cell lines (C33-A and HT-3) than in the HPV-positive cell lines, suggesting a possible role of WIG-1 in HPV-negative cervical carcinogenesis. The authors reported statistically significant higher WIG-1 protein staining intensity in HPV-independent cervical cancer tumors compared with HPV-associated tumors, both in squamous $(p=0.002)$ and in adenocarcinomas $(p=0.049) .{ }^{39}$

Differences in expression levels of miRNAs - a class of small non-coding RNA molecules that regulate key cellular processesbetween high risk-HPV E6/E7 mRNA positive and high risk-HPV E6/ E7 mRNA negative cervical cancer tissue samples have been evaluated. While miR-9 was downregulated, ${ }^{40}$ miR-21 and miR- $155^{31}$ were upregulated in high risk-HPV E6/E7 mRNA negative cancer tissue samples. The miRNA regulation mechanism involves high risk-HPV E6/E7 proteins; therefore, the absence of these proteins could be deregulating the expression of miR9, miR21, and miR155, impacting regulation of metastasis, cell proliferation, inflammationassociated carcinogenesis, and tumor metabolism. ${ }^{31} 40$

The Cancer Genome Atlas (TCGA) Research Network ${ }^{4}$ reports that HPV-independent cervical cancer encompassed a distinct subgroup within the $\mathrm{CpG}$ island hypermethylated (CIMP)-low cluster, with a lower mean promoter methylation, typically observed on healthy epithelial tissue. Functional epigenetic analysis showed differential subnetworks for HPV-associated and HPV-independent tumors, with one common subnetwork centered around Forkhead Box A2 (FOXA2) gene (high DNA-methylation and low gene expression in HPV-positive cases). HPV-independent tumors also have a lower activation of NF- $\mathrm{B}, \mathrm{p} 53$, and MAPK signaling, a significantly higher epithelial-mesenchymal transition (EMT) MRNA score, and a lower frequency of APOBEC (apolipoprotein B mRNA editing enzyme, catalytic polypeptide-like) mutagenesis signature, and are characterized by mutations in KRAS, ARID1A, and PTEN.

Liu et $\mathrm{al}^{30}$ identified 17 differentially expressed genes between HPV-positive and HPV-negative tumors. Following mRNA and protein level determinations, the authors reported seven genes with significantly higher expression in HPV-negative cervical cancer cells and tissues than in HPV-positive cervical cancer and normal cells or tissues. Particularly, MEX3A, an RNA binding gene, and TTYH3, a chloride-channel-responsive gene, correlated with shorter overall survival of patients with HPV-independent cervical cancer, representing a possible new therapeutic target.

Based on the expression of HPV E6/E7 oncogenes, Banister et $\mathrm{al}^{42}$ classified cervical tumors into HPV-active and HPV-inactive, based on the transcriptional state of the mRNA. The HPV-inactive group is associated with lower DNA methylation levels and therefore overexpression of several genes. According to the nonsynonymous and synonymous mutation profile, the cancer driver genes PTEN, p53, CTNNB1, AKT, ARID1A, and ARID5B tend to be mutated, independently of the APOBEC pathway, suggesting that HPV-inactive tumors use alternative pathways to sustain tumor growth; additionally, the expression of inflammatory associated genes is decreased.

\section{Clinical Outcomes of HPV-Independent Tumors}

Currently, the proposed first-line treatment for early stages of cervical cancer (stage IA1 with lymph vascular space invasion to IB2 and IIA1 International Federation of Gynecology and Obstetrics (FIG0) 2018) is an open radical hysterectomy with pelvic lymph node assessment. ${ }^{43}{ }^{44}$ Adjuvant treatment with chemoradiotherapy may be necessary based on pathologic findings. For advanced stages (stage IB3, IIA2 to IVA FIG0 2018) the standard treatment is concomitant platinum-based chemoradiotherapy, and for metastatic disease (IVB FIG0 2018) platinum-based therapy with bevacizumab. ${ }^{43-45}$

Primary treatment of cervical cancer is based on clinical, imaging, and pathological results. However, there is no specific treatment based on histological type, genomic alteration or HPV status defined in the current guidelines. Several studies have reported that patients with HPV-independent tumors could have a worse prognosis than HPV-associated tumors; however, the clinical impact of HPV detection to determine treatment is still not clear. ${ }^{46-49}$ There is no prospective evidence evaluating the outcomes of patients with HPV-independent cervical cancer.

A retrospective cohort study of 136 patients ${ }^{50}$ with cervical cancer, including squamous cell carcinoma and adenocarcinoma, showed that of 14 initially HPV-independent tumors, determined by the Hybrid Capture system (Qiagen, USA), only eight were confirmed by PCR. These patients had a worse disease-free survival (51.9 vs 109.9 months; $p=0.010$ ) and this was considered a prognostic factor even after multivariate analysis. The authors found that despite being more common in adenocarcinomas, these poor outcomes were also demonstrated in non-keratinizing squamous histological types. ${ }^{51}$

Some additional retrospective studies analyzed the association between HPV negativity and oncological outcomes. In a study including 248 patients-108 patients who underwent surgery and 140 patients treated with chemoradiation-Chong et al $^{52}$ reported that $18.5 \%$ of cervical cancers were HPV-independent and those tumors were associated in a multivariate analysis with poorer disease-free survival when compared with HPV-associated tumors (HR 3.97, 95\% Cl 1.84 to 8.58; $p=0.0005$ ). Several reports have demonstrated a similar pattern in patients with HPV-associated head and neck squamous cell carcinoma, showing greater radiosensitivity and better prognosis, and this is strongly related to the molecular differences between HPV-associated and HPVindependent tumors. ${ }^{53}$ Another retrospective analysis included 214 tumors, ${ }^{37}$ classified as squamous cell carcinoma, adenocarcinoma, adenosquamous, or neuroendocrine. Using reverse hybridization for HPV genotyping and p16 immunostaining, the authors found a 10\% rate of HPV-independent tumors. Patients with HPV-independent tumors had higher rates of lymph node invasion $(67 \%$ vs $36 \%$, $p<0.01)$ and worse disease-free survival (59.8 vs 132.2 months, $p<0.01)$ and overall survival $(77.0$ vs 153.8 months, $p=0.01$ ) compared with women with HPV-associated tumors. However, only advanced FIGO stage and lymph node metastases after multivariate analysis were associated with a poor prognosis.

A recent retrospective multicenter study evaluating prognostic biomarkers analyzed 464 cases with IB endocervical 


\section{Review}

adenocarcinomas using the International Endocervical Adenocarcinoma Criteria and Classification system and no molecular tests. They identified on multivariate analysis that the HPV-independent status was associated with worse recurrence-free survival (HR 2.31, Cl 95\% 1.02 to 5.46; $p=0.05)$. The other associated factors for this cohort were the lymph vascular invasion and the presence of lymph node metastasis. ${ }^{54}$

Finally, in a re-testing study ${ }^{55}$ including FIGO stage I-IV of 37 initially HPV-negative samples (corresponding to $14 \%$ of all the analyzed tumors), including squamous cell carcinoma and adenocarcinomas, only half were confirmed as HPV-independent. These tumors had a worse cancer-specific survival at 5 years $(27 \%$ vs $69 \%, p=0.009$ ) and a lower recurrence rate, although this was nonsignificant ( $27 \%$ vs $50 \%, p=0.061)$. A systematic review and metaanalysis was recently published exploring the value of HPV status in patients with cervical cancer. ${ }^{56}$ The analysis of 17 retrospectives studies including 2838 patients showed that the oncological outcomes of patients with HPV-associated cancers were different. The overall survival was higher in this population (HR 0.610, 95\% Cl 0.457 to $0.814 ; p=0.001$ ), as was the disease-free survival (HR $0.362,95 \% \mathrm{Cl} 0.252$ to $0.519 ; \mathrm{p}<0.001$ ), compared with HPVindependent cancer patients. This review has some limitations, given the lack of a registered protocol, the absence of a methods section, and the performance of meta-analysis even when high heterogeneity was present. It also has to be mentioned that the methods for HPV detection and the source of tissue varied through the different primary studies.

The American Joint Committee on Cancer (AJCC) ${ }^{57}$ in its 9th edition, within the key modifications for cervical cancer, suggested defining HPV status as associated or independent, considering the evidence describing worse oncologic outcomes in the HPVindependent tumors. Despite the modest evidence that defines pathological and clinical characteristics of these tumors, the determination of HPV status prior to the start of treatment could be a useful tool for discussion of disease prognosis and potentially for establishing closer surveillance in these patients. It also encourages further research with the aim of determining carcinogenesis and biological behavior that might lead to personalized treatment and improved oncological outcomes.

\section{Etiology of HPV-Independent Tumors}

Thus far, it is difficult to explain the development of HPV-independent tumors, but the 'hit and run viral theory' could explain the absence of the viral genome in these cases. Viruses associated with human cancers promote an inflammatory process, change the microenvironment and cellular metabolism, and are associated with genomic instability. The 'hit and run theory' proposes that once a viral infection has caused sufficient cellular alteration, expression of viral proteins or viral infection is no longer required for tumor maintenance, and, consequently, the virus may be lost during cancer progression (Figure 1). ${ }^{58} 59$

It has been proposed that the $E 6 / E 7$ oncogenes start the process of carcinogenesis, but as the mutations accumulate over time, transcription of the viral genes is no longer necessary and therefore they are lost. ${ }^{59}$ Additionally, it has been proposed that the 'hit and run' theory of oncogenesis may also leave permanent traces through epigenetic dysregulation. Chromatin remodeling may expose hotspots for viruses to impair transcriptional regulation, DNA repair, and permanent epigenetic alterations in the infected cell, as E7 HR-HPV oncoprotein that stimulates DNA methyltransferase 1 (Dnmt1) activity. ${ }^{60}$ During the 'hit and run' process, the transient but regular presence of viral genomes or parts thereof in a pre-invasive stage of the respective tumor would be considered; thus the initial persistent infection with HPV in pre-invasive lesions could be the necessary hit for the development of HPV-independent cervical cancer after the viral run. ${ }^{60}$ The existence of HPV-independent preinvasive lesions has not been established thus far. However, it was recently reported that two of three HPV-independent pre-invasive

\section{Hit and Run Theory}

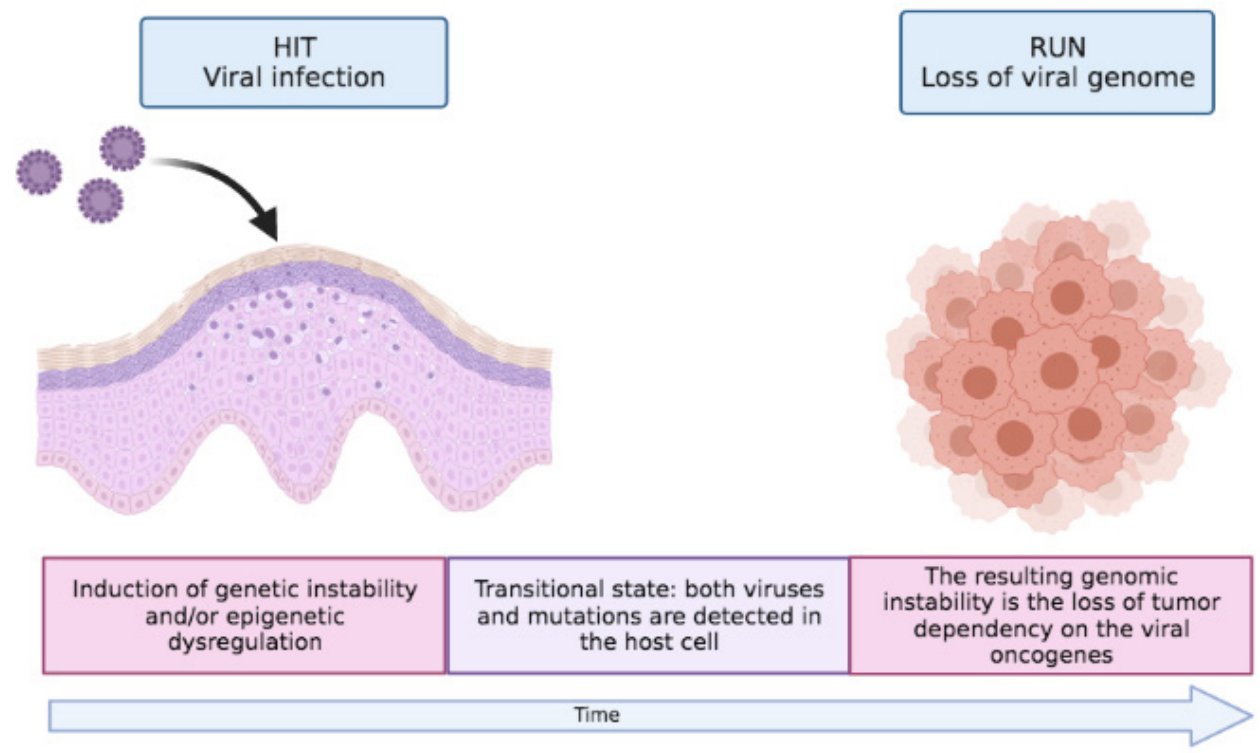

Figure 1 Schematic representation of the hypothetical hit and run mechanism. Created with BioRender.com. Adapted from Ferreira et $\mathrm{al}^{59}$ and Niller et al. ${ }^{60}$ 
Table 2 HPV-independent cervical cancer reports

\begin{tabular}{|c|c|c|c|c|}
\hline Author & Sample histology & $\begin{array}{l}\text { Negative cases } \\
\text { N (\%) }\end{array}$ & $\begin{array}{l}\text { Negative results according } \\
\text { to sample histology }\end{array}$ & Technique \\
\hline Riou et al ${ }^{48}$ & $89 \mathrm{SQ}, 17 \mathrm{ADC}$ & $17 / 106(16.03)$ & $15 \mathrm{SQ}, 2 \mathrm{ADC}$ & Southern blot, PCR \\
\hline Shikano et al ${ }^{32}$ & $39 \mathrm{ADC}$ & $14 / 39(14.35)$ & $14 \mathrm{ADC}$ & $\mathrm{CISH}$ \\
\hline Brewer et $\mathrm{al}^{34}$ & $\begin{array}{l}30 \text { LCNK, } 23 \text { LCK, } 7 \text { ADC, } \\
5 \text { ADS, } 1 \text { CC }\end{array}$ & $5 / 66(7.57)$ & Not reported & MY09/11-E6 \\
\hline Lo et $\mathrm{al}^{51}$ & $107 \mathrm{SQ}, 14 \mathrm{ADC}$ & $26 / 121$ (21.48) & $23 \mathrm{SQ}, 3 \mathrm{ADC}$ & MY09/11 - sequencing \\
\hline Kedzia et $\mathrm{al}^{33}$ & $47 \mathrm{SQ}$ & $15 / 47(31.91)$ & $15 \mathrm{SQ}$ & MY09/11 - E6 \\
\hline Park et $\mathrm{a}^{35}$ & 26 ADC unusuals & $26 / 26(100)$ & 26 ADC unusuals & SPF10-LiPA system \\
\hline Xu et $\mathrm{al}^{39}$ & $13 \mathrm{SQ}, 25 \mathrm{ADC}$ & $17 / 38(44.73)$ & $4 \mathrm{SQ}, 13 \mathrm{ADC}$ & Multiplex PCR \\
\hline Liu et $\mathrm{al}^{40}$ & $\begin{array}{l}89 \mathrm{SQ}, 10 \mathrm{ADC}, 2 \mathrm{CC}, 1 \\
\text { undifferentiated }\end{array}$ & $14 / 101(13.86)$ & Not reported & E6/E7 mRNA \\
\hline $\begin{array}{l}\text { Rodríguez-Carunchio } \\
\text { et al }{ }^{50}\end{array}$ & $104 \mathrm{SQ}, 32 \mathrm{ADC}$ & $8 / 136(5.88)$ & $3 \mathrm{SQ}, 5 \mathrm{ADC}$ & $\begin{array}{l}\text { HC2, SPF10-LiPA system, } \\
\text { GP5+/6+, E7-specific assay }\end{array}$ \\
\hline Omori et $\mathrm{al}^{36}$ & $\begin{array}{l}36 \mathrm{ADC} \text { usual, } 8 \mathrm{ADC} \\
\text { gastric }\end{array}$ & $14 / 44(31.81)$ & 6 ADC usuals, 8 ADC gastrics & ISH, PCR \\
\hline Park et $\mathrm{al}^{31}$ & $50 \mathrm{SQ}, 2 \mathrm{ADC}$ & $15 / 52(28.84)$ & Not reported & E6/E7 mRNA \\
\hline Burk et $a^{4}$ & $144 \mathrm{SQ}, 31 \mathrm{ADC}, 3 \mathrm{ADS}$ & 9/178 (5.05) & $4 \mathrm{SQ}, 5 \mathrm{ADC}$ & RNA seq \\
\hline Banister et al ${ }^{42}$ & 212 SQ, 44 ADC, 5 ADS & $20 / 261(7.70)$ & $10 \mathrm{SQ}, 8 \mathrm{ADC}, 2 \mathrm{ADS}$ & RNA seq (E6E7/total genes) \\
\hline Chong et $\mathrm{a}^{52}$ & $210 \mathrm{SQ}, 38 \mathrm{ADC} / \mathrm{ADS}$ & $46 / 248(18.50)$ & $33 \mathrm{SQ}, 13 \mathrm{ADC} / \mathrm{ADS}$ & $\begin{array}{l}\text { PAN Array HPV Genotyping } \\
\text { Chip/Anyplex II HPV28 }\end{array}$ \\
\hline Nicolás et $\mathrm{al}^{37}$ & $\begin{array}{l}168 \mathrm{SQ}, 39 \mathrm{ADC}, 4 \mathrm{ADS}, 3 \\
\text { neuroendocrines }\end{array}$ & $21 / 214(9.81)$ & $\begin{array}{l}12 \mathrm{SQ}, 6 \mathrm{ADC}, 1 \mathrm{ADS}, 2 \\
\text { neuroendocrines }\end{array}$ & SPF10-LiPA system \\
\hline Kaliff et al ${ }^{55}$ & $\begin{array}{l}169 \mathrm{SQ}, 27 \mathrm{ADC}, 4 \mathrm{ADS}, 2 \\
\text { neuroendocrines }\end{array}$ & $14 / 202(6.9)$ & $3 \mathrm{SQ}, 9 \mathrm{ADC}, 2 \mathrm{ADS}$ & $\begin{array}{l}\text { Anyplex II HPV28, RT-PCR E6/ } \\
\text { E7 }\end{array}$ \\
\hline
\end{tabular}

ADC, adenocarcinoma; ADS, adenosquamous; CC, clear cells; CISH, chromogenic in situ hybridization; HPV, human papillomavirus; ISH, in situ hybridization; LCK, large cell keratinizing; LCNK, large cell non-keratinizing; PCR, polymerase chain reaction; SQ, squamous.

cervical lesions showed diffuse $\mathrm{p} 16^{\text {ink4a }}$ staining, similar to the pattern shown in HPV-associated lesions. The authors excluded somatic or germline mutations in the $R B$ gene or the CDKN2A gene encoding the $\mathrm{p} 16^{\text {ink4a }}$ protein, ${ }^{61}$ which could suggest the action of the 'hit-and-run' mechanism.

\section{NEW PERSPECTIVES}

With the development of new technologies for HPV detection, the detection rate of HPV-negative cases has decreased. ${ }^{9}$ However, several studies continue reporting HPV-independent cervical cancer through different methodologies, including deep sequencing, both in cases of adenocarcinomas and squamous cell carcinomas (Table 2). Additionally, the distinctive molecular profile of these HPV-independent tumors provides information regarding the presence of tumors with a different biological behavior, mediated by the alteration of signaling pathways independent of viral infection, and highlighting alterations in PTEN, KRAS, p53, CTNNB1, ARID1A, and $A R I D 5 B B^{42}$ With these data, further investigations based on the evaluation of these proteins as tumor markers in cases of HPVindependent cervical cancer could have some implications for treatment.

A patient with cervical cancer with an HPV-negative test may constitute a biologically distinct subgroup, which may be associated with advanced FIGO stage and a poor prognosis, and may require a different therapeutic strategy. ${ }^{24} 42$ It is well known that in HPV-independent oropharyngeal cancer, the response rate to chemotherapy and radiation treatment is lower than in HPVassociated cases ${ }^{53}$ Therefore, the lower progression-free survival and overall survival of HPV-independent cervical tumors may be associated with low responses to current standard treatment. However, to date there are no current data to support this hypothesis. Banister et $a^{A^{2}}$ proposed that, due to the somatic mutations shown by HPV-independent tumors, PI3K/mTOR inhibitors and tyrosine kinases inhibitors (dasatinib) may improve the response rate in these patients.

The lower expression of inflammatory associated genes ${ }^{42}$ suggest that HPV-independent cervical cancers may have a worse response rate to checkpoint inhibitors-based immunotherapy, such as programmed death protein 1/programmed cell death ligand 1 (PD1/PD-L1) inhibitors. The KEYNOTE-028 trial $^{63}$ and CHECKMATE-358 trial ${ }^{64}$ demonstrated that patients with HPV-associated cervical cancer (squamous cell type) had improved outcomes due to an elevated proportion of TCD8 + infiltrating lymphocytes (TILSs) and PD-L1 ${ }^{6566}$ However, Chen et al ${ }^{67}$ reported no significant difference in PD-L1 expression among different histologic types of endocervical adenocarcinomas.

\section{CONCLUSIONS}

HPV-independent cervical cancer constitutes a unique biological entity with a different molecular profile when compared with HPV-associated tumors. The absence of p16 and the presence of founder mutations in genes such as p53, KRAS, ARID1A, and PTEN 
characterize the HPV-independent tumors; thus the WHO recommends the use of HPV testing and p16 immunostaining for differentiation between HPV-associated and HPV-independent cervical cancer. HPV-independent tumors are associated with both adenocarcinomas and squamous histologic subtypes, with lymph node involvement in early stages, more distant metastasis, and generally worse oncological outcomes. However, there is no prospective information available that evaluates different interventions according to HPV status that will lead to changing clinical practice yet, and there is no specific treatment based on HPV status. There is need for future research, encouraging investigators to report on clinical outcomes, evaluating the overall response rates to specific treatments, and to consider new biomarkers to establish more accurate prognostics factors.

\section{Author affiliations}

'Laboratorio de Genética Molecular, Instituto de Oncología y Hematología, Caracas, Bolivarian Republic of Venezuela

${ }^{2}$ Department of Gynecologic Oncology, Instituto Nacional de Cancerologia, Bogota, Colombia

${ }^{3}$ Obstetrics and Gynecology. Division of Gynecological Oncology, Hospital General del Este "Dr. Domingo Luciani", Caracas, Bolivarian Republic of Venezuela ${ }^{4}$ Clínica ASTORGA, Medellín, Colombia

Twitter Andreina Fernandes @AndreFernandes2, David Viveros-Carreño @dviverosc, Jorge Hoegl @oncohoegl and Rene Pareja @RParejaGineOnco

Contributors AF, DV and RP designed the research; DV, JH and MA searched and reviewed the data; AF, DV, JH, MA wrote the paper; RP made the editorial revision. All the authors reviewed the manuscript and approved the final version.

Funding The authors have not declared a specific grant for this research from any funding agency in the public, commercial or not-for-profit sectors.

Competing interests None declared.

Patient consent for publication Not applicable.

Provenance and peer review Not commissioned; externally peer reviewed.

\section{ORCID iDs}

Andreina Fernandes http://orcid.org/0000-0003-0589-2696

David Viveros-Carreño http://orcid.org/0000-0001-9395-0627

Jorge Hoegl http://orcid.org/0000-0003-0063-3871

Rene Pareja http://orcid.org/0000-0003-0093-0438

\section{REFERENCES}

1 Sung H, Ferlay J, Siegel RL, et al. Global cancer statistics 2020: GLOBOCAN estimates of incidence and mortality worldwide for 36 cancers in 185 countries. CA Cancer J Clin 2021;71:209-49.

2 Arbyn M, Weiderpass E, Bruni L, et al. Estimates of incidence and mortality of cervical cancer in 2018: a worldwide analysis. Lancet Glob Health 2020;8:e191-203.

3 Schiffman M, Doorbar J, Wentzensen N, et al. Carcinogenic human papillomavirus infection. Nat Rev Dis Primers 2016;2.

4 Cancer Genome Atlas Research Network, Albert Einstein College of Medicine, Analytical Biological Services, et al. Integrated genomic and molecular characterization of cervical cancer. Nature 2017;543:378-84.

5 zur Hausen $\mathrm{H}$. Papillomaviruses in the causation of human cancers a brief historical account. Virology 2009;384:260-5.

6 Guan P, Howell-Jones R, Li N, et al. Human papillomavirus types in 115,789 HPV-positive women: a meta-analysis from cervical infection to cancer. Int J Cancer 2012;131:2349-59.

7 WHO Classification of Tumours Editorial Board. Female Genital Tumours. In: WHO classification of tumours: female genital tumours. 5 edn. Lyon: International Agency for Research on Cancer, 2020: 631 .

8 Tjalma W. HPV negative cervical cancers and primary HPV screening. Facts Views Vis Obgyn 2018;10:107-13.

9 Li N, Franceschi S, Howell-Jones R, et al. Human papillomavirus type distribution in 30,848 invasive cervical cancers worldwide: variation by geographical region, histological type and year of publication. Int J Cancer 2011;128:927-35.

10 Perkins RB, Guido RS, Castle PE. ASCCP risk-based management consensus guidelines for abnormal cervical cancer screening tests and cancer precursors. J Low Genit Tract Dis 2019;2020:102-31.

11 Simelela PN. WHO global strategy to eliminate cervical cancer as a public health problem: an opportunity to make it a disease of the past. Int J Gynaecol Obstet 2021;152:1-3.

12 Arbyn M, Snijders PJF, Meijer CJLM, et al. Which high-risk HPV assays fulfil criteria for use in primary cervical cancer screening? Clin Microbiol Infect 2015;21:817-26.

13 de Sanjose S, Holme F. What is needed now for successful scale-up of screening? Papillomavirus Res 2019;7:173-5.

14 Schiffman M, de Sanjose S. False positive cervical HPV screening test results. Papillomavirus Res 2019;7:184-7.

15 Poljak M, Oštrbenk Valenčak A, Gimpelj Domjanič G, et al. Commercially available molecular tests for human papillomaviruses: a global overview. Clin Microbiol Infect 2020;26:1144-50.

16 Chrysostomou AC, Kostrikis LG. Methodologies of primary HPV testing currently applied for cervical cancer screening. Life 2020;10:290.

17 Bhatla N, Singhal S. Primary HPV screening for cervical cancer. Best Pract Res Clin Obstet Gynaecol 2020;65:98-108.

18 Abreu ALP, Souza RP, Gimenes F, et al. A review of methods for detect human papillomavirus infection. Virol J 2012;9:262.

19 Arroyo LS, Smelov V, Bzhalava D, et al. Next generation sequencing for human papillomavirus genotyping. J Clin Virol 2013;58:437-42.

20 Arroyo Mühr LS, Bzhalava D, Lagheden C, et al. Does human papillomavirus-negative condylomata exist? Virology 2015;485:283-8.

21 Arroyo Mühr LS, Hultin E, Bzhalava D, et al. Human papillomavirus type 197 is commonly present in skin tumors. Int $J$ Cancer 2015;136:2546-55.

22 Tsakogiannis D, Gartzonika C, Levidiotou-Stefanou S. Molecular approaches for HPV genotyping and HPV-DNA physical status. Expert Rev Mol Med;6:e1.

23 Poljak M, Kocjan BJ, Oštrbenk A, et al. Commercially available molecular tests for human papillomaviruses (HPV): 2015 update. $J$ Clin Virol 2016;76 Suppl 1:S3-13.

24 Xing B, Guo J, Sheng Y, et al. Human papillomavirus-negative cervical cancer: a comprehensive review. Front Oncol 2020;10:606335

25 Petry KU, Liebrich C, Luyten A, et al. Surgical staging identified false HPV-negative cases in a large series of invasive cervical cancers. Papillomavirus Res 2017;4:85-9.

26 Bzhalava D, Johansson $\mathrm{H}$, Ekström J, et al. Unbiased approach for virus detection in skin lesions. PLoS One 2013;8:e65953.

27 Arroyo Mühr LS, Bzhalava Z, Hortlund M, et al. Viruses in cancers among the immunosuppressed. Int J Cancer 2017;141:2498-04.

28 Arroyo Mühr LS, Lagheden C, Lei J, et al. Deep sequencing detects human papillomavirus (HPV) in cervical cancers negative for HPV by PCR. Br J Cancer 2020;123:1790-5.

29 Liu D, Zhou P, Zhang L. Differential expression of Oct4 in HPVpositive and HPV-negative cervical cancer cells is not regulated by DNA methyltransferase 3A. Tumor Biol 2011;32:941-50.

30 Liu Y, Xu Y, Jiang W, et al. Discovery of key genes as novel biomarkers specifically associated with HPV-negative cervical cancer. Mol Ther Methods Clin Dev 2021;21:492-506.

31 Park S, Eom K, Kim J, et al. MiR-9, miR-21, and miR-155 as potential biomarkers for HPV positive and negative cervical cancer. BMC Cancer 2017;17:658.

32 Shikano K, Sasano H, Ito K, et al. The correlation between HPV infection and cell proliferative activity in uterine cervical adenocarcinoma. Tohoku J Exp Med 1993;169:279-88.

33 Kedzia W, Schmidt M, Frankowski A, et al. Immunohistochemical assay of p53, cyclin D1, c-erbB2, EGFR and Ki-67 proteins in HPV-positive and HPV-negative cervical cancers. Folia Histochem Cytobiol 2002;40:37-41.

34 Brewer CA, Liao SY, Wilczynski SP, et al. A study of biomarkers in cervical carcinoma and clinical correlation of the novel biomarker MN. Gynecol Oncol 1996;63:337-44.

35 Park KJ, Kiyokawa T, Soslow RA. Unusual endocervical adenocarcinomas. Am J Surg Pathol 2011;35:633-46.

36 Omori M, Hashi A, Kondo T, et al. Dysregulation of CDK inhibitors and p53 in HPV-negative endocervical adenocarcinoma. Int $J$ Gynecol Pathol 2015;34:196-203.

37 Nicolás I, Marimon L, Barnadas E. HPV-negative tumors of the uterine cervix. Modern Pathol 2019;32:1189-96.

38 Houghton O, Jamison J, Wilson R, et al. P16 immunoreactivity in unusual types of cervical adenocarcinoma does not reflect human papillomavirus infection. Histopathology 2010;57:342-50. 
39 Xu L-D, Muller S, Thoppe SR, et al. Expression of the p53 target Wig-1 is associated with HPV status and patient survival in cervical carcinoma. PLoS One 2014;9:e111125.

40 Liu W, Gao G, Hu X, et al. Activation of miR-9 by human papillomavirus in cervical cancer. Oncotarget 2014;5:11620-30.

41 Sedaghat Y, Mazur C, Sabripour M, et al. Genomic analysis of wig-1 pathways. PLoS One 2012;7:e29429.

42 Banister CE, Liu C, Pirisi L, et al. Identification and characterization of HPV-independent cervical cancers. Oncotarget 2017;8:13375-86.

43 Motter A, Frederick P, Gaffney DK. NCCN guidelines version 1.2021. Cervical cancer 2020.

44 Cibula D, Pötter R, Planchamp F, et al. The European Society of Gynaecological Oncology/European Society for Radiotherapy and Oncology/European Society of Pathology guidelines for the management of patients with cervical cancer. Int J Gynecol Cancer 2018;28:641-55.

45 Tewari KS, Sill MW, Penson RT, et al. Bevacizumab for advanced cervical cancer: final overall survival and adverse event analysis of a randomised, controlled, open-label, phase 3 trial (Gynecologic Oncology Group 240). Lancet 2017;390:1654-63.

46 Lindel K, Burri P, Studer HU, et al. Human papillomavirus status in advanced cervical cancer: predictive and prognostic significance for curative radiation treatment. Int J Gynecol Cancer 2005;15:278-84.

47 Harima Y, Sawada S, Nagata K, et al. Human papilloma virus (HPV) DNA associated with prognosis of cervical cancer after radiotherapy. Int J Radiat Oncol Biol Phys 2002;52:1345-51.

48 Riou G, Favre M, Jeannel D, et al. Association between poor prognosis in early-stage invasive cervical carcinomas and nondetection of HPV DNA. Lancet 1990;335:1171-4.

49 Crook T, Vousden KH. Properties of p53 mutations detected in primary and secondary cervical cancers suggest mechanisms of metastasis and involvement of environmental carcinogens. Embo J 1992;11:3935-40.

50 Rodríguez-Carunchio L, Soveral I, Steenbergen RDM, et al. HPVnegative carcinoma of the uterine cervix: a distinct type of cervical cancer with poor prognosis. BJOG 2015;122:119-27.

51 Lo KW, Cheung TH, Chung TK, et al. Clinical and prognostic significance of human papillomavirus in a Chinese population of cervical cancers. Gynecol Obstet Invest 2001;51:202-7.

52 Chong GO, Lee YH, Han HS, et al. Prognostic value of pre-treatment human papilloma virus DNA status in cervical cancer. Gynecol Oncol 2018;148:97-102.

53 Kimple RJ, Smith MA, Blitzer GC, et al. Enhanced radiation sensitivity in HPV-positive head and neck cancer. Cancer Res 2013;73:4791-800.
54 Stolnicu S, Boros M, Hoang L, et al. FIGO 2018 stage IB endocervical adenocarcinomas: an international study of outcomes informed by prognostic biomarkers. Int J Gynecol Cancer 2021;31:177-84.

55 Kaliff M, Karlsson MG, Sorbe B, et al. HPV-negative tumors in a Swedish cohort of cervical cancer. Int J Gynecol Pathol 2020;39:279-88.

56 Li P, Tan Y, Zhu L-X, et al. Prognostic value of HPV DNA status in cervical cancer before treatment: a systematic review and metaanalysis. Oncotarget 2017;8:66352-9.

57 Olawaiye AB, Baker TP, Washington MK, et al. The new (version 9) American Joint Committee on Cancer tumor, node, metastasis staging for cervical cancer. CA Cancer J Clin 2021;71:287-98.

58 Gaglia MM, Munger K. More than just oncogenes: mechanisms of tumorigenesis by human viruses. Curr Opin Virol 2018;32:48-59.

59 Ferreira DA, Tayyar Y, Idris A. A "hit-and-run" affair - a possible link for cancer progression in virally driven cancers. Biochim Biophys Acta Rev Cancer 1875;2021.

60 Niller $\mathrm{HH}$, Wolf $\mathrm{H}$, Minarovits J. Viral hit and run-oncogenesis: genetic and epigenetic scenarios. Cancer Lett 2011;305:200-17.

61 Regauer S, Reich O, Kashofer K. HPV-negative squamous cell carcinomas of the cervix with special focus on intraepithelial precursor lesions. Am J Surg Pathol 2021:1-12.

62 Lei J, Ploner A, Lagheden C, et al. High-risk human papillomavirus status and prognosis in invasive cervical cancer: a nationwide cohort study. PLoS Med 2018;15:e1002666.

63 Frenel J-S, Le Tourneau C, O'Neil B, et al. Safety and efficacy of pembrolizumab in advanced, programmed death ligand 1-positive cervical cancer: results from the phase lb KEYNOTE-028 trial. J Clin Oncol 2017;35:4035-41.

64 Naumann RW, Hollebecque A, Meyer T, et al. Safety and efficacy of nivolumab monotherapy in recurrent or metastatic cervical, vaginal, or vulvar carcinoma: results from the phase I/II CheckMate 358 trial. J Clin Oncol 2019;37:2825-34.

65 Mezache L, Paniccia B, Nyinawabera A, et al. Enhanced expression of PD L1 in cervical intraepithelial neoplasia and cervical cancers. Mod Pathol 2015;28:1594-602.

66 Andersen AS, Koldjaer Sølling AS, Ovesen T, et al. The interplay between HPV and host immunity in head and neck squamous cell carcinoma. Int J Cancer 2014;134:2755-63.

67 Chen L, Lucas E, Zhang X. PD-L1 expression in HPV-independent cervical adenocarcinoma and its prognostic significance. Histopathology 2021. 